\title{
Effectiveness of seasonal trivalent inactivated influenza vaccine in preventing influenza hospitalisations and primary care visits in Auckland, New Zealand, in 2013
}

N Turner (n.turner@auckland.ac.nz)1, N Pierse2, A Bissielo3, Q S Huang3, S Radke1,3, M G Baker2, M A Widdowson4, H Kelly5,6, on behalf of the SHIVERS investigation team7

1. The University of Auckland, Auckland, New Zealand

2. University of Otago, Wellington, New Zealand

3. Institute of Environmental Science and Research, Wellington, New Zealand

4. Centers for Disease Control and Prevention, Atlanta, GA, United States

5. Australian National University, Canberra, Australia

6. Victorian Infectious Diseases Reference Laboratory, Melbourne, Australia

7. Members of the team are listed at the end of the article

Citation style for this article:

Turner N, Pierse N, Bissielo A, Huang QS, Radke S, Baker MG, Widdowson MA, Kelly H, on behalf of the SHIVERS investigation team. Effectiveness of seasonal trivalent inactivated influenza vaccine in preventing influenza hospitalisations and primary care visits in Auckland, New Zealand, in 2013 . Euro Surveill. 2014;19(34): pii=20884. Available online: http://www.eurosurveillance.org/ViewArticle.aspx?Articleld=20884

This study reports the first vaccine effectiveness (VE) estimates for the prevention of general practice visits and hospitalisations for laboratory-confirmed influenza from an urban population in Auckland, New Zealand, in the same influenza season (2013). A case test-negative design was used to estimate propensityadjusted VE in both hospital and community settings. Patients with a severe acute respiratory infection (SARI) or influenza-like illness (ILI) were defined as requiring hospitalisation (SARI) or attending a general practice (ILI) with a history of fever or measured temperature $\geq 38{ }^{\circ} \mathrm{C}$, cough and onset within the past 10 days. Those who tested positive for influenza virus were cases while those who tested negative were controls. Results were analysed to 7 days post symptom onset and adjusted for the propensity to be vaccinated and the timing during the influenza season. Influenza vaccination provided $52 \%(95 \% \mathrm{Cl}: 32$ to 66$)$ protection against laboratory-confirmed influenza hospitalisation and $56 \%$ ( $95 \% \mathrm{Cl}: 34$ to 70 ) against presenting to general practice with influenza. VE estimates were similar for all types and subtypes. This study found moderate effectiveness of influenza vaccine against medically attended and hospitalised influenza in New Zealand, a temperate, southern hemisphere country during the 2013 winter season.

\section{Introduction}

Influenza infection causes a major burden of illness in adults and children $[1,2]$. Seasonal trivalent influenza vaccines (TIVs) are effective in preventing a range of laboratory-confirmed outcomes [3], but effectiveness varies by severity and season, the presence of comorbidities and age $[4,5]$.
The SHIVERS (Southern Hemisphere Influenza Vaccine Effectiveness, Research and Surveillance) study has allowed estimation of vaccine effectiveness (VE) against influenza illness requiring hospitalisation since 2012 and against influenza illness requiring primary care (general practice) since 2013.

In New Zealand, seasonal non-adjuvanted inactivated trivalent influenza vaccine is available annually free of charge to all adults aged 65 years and over, pregnant women and all those over six months of age with chronic medical conditions that are likely to increase the severity of the infection. Influenza vaccines are also available on the private market for all others over six months of age. Two commercial vaccine products were available in the New Zealand market in 2013: Fluarix (GlaxoSmithKline) and Fluvax (bioCSL). Both vaccines contained $\mathrm{A} /$ California/7/2009 ( $\left.\mathrm{H}_{1} \mathrm{~N}_{1}\right)$-like virus, $A /$ Victoria/36/2011 ( $\left.\mathrm{H}_{3} \mathrm{~N}_{2}\right)$-like virus and $\mathrm{B} /$ Wisconsin/1/2010-like virus (belonging to $\mathrm{B} /$ Yamagata/16/88 lineage).

Using the case test-negative design, we estimated the effectiveness of seasonal trivalent inactivated influenza vaccine in preventing laboratory-confirmed influenza in patients hospitalised with severe acute respiratory infections (SARI) and in patients presenting to general practice with an influenza-like illness (ILI) during the 2013 influenza season, which is from March to September in New Zealand.

\section{Methods}

Ethics approval for the study was obtained from the Northern A Health and Disability Ethics Committee (NTX/11/11/102 AM02). 
Study participants with influenza-like illness who were influenza positive or negative by week, New Zealand, 2013 influenza season

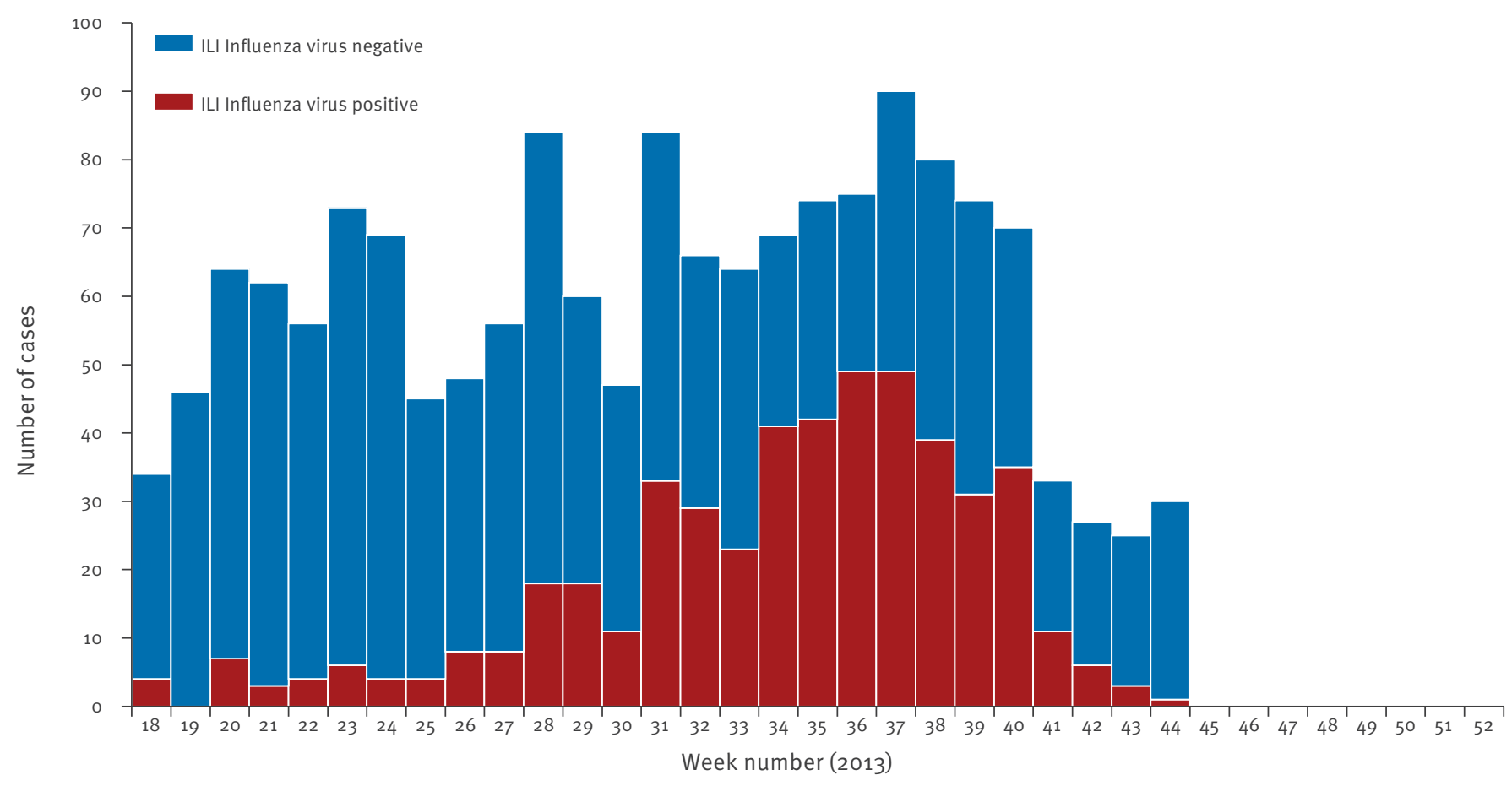

ILI: influenza-like illness.

Weeks 18 to 52 are shown (29 April to 31 December 2013).

Study design

In both hospital and community settings, we conducted a study using a standard case test-negative design [6], drawing on an urban population of approximately 838,000 people in Central, South and East Auckland [7].

For community cases, we recruited 18 sentinel general practices with 103,884 enrolled patients. Patients in these sentinel practices were broadly representative of the ethnically diverse urban population of Auckland by age and sex distribution, but with more Pacific people ( $27 \%$ in the practices compared with $15 \%$ in the source population) and slightly fewer people of Asian descent ( $14 \%$ versus $19 \%$, respectively)[7].

The practices recruited individuals aged six months and older who presented to a general practitioner or practice nurse with ILI, defined as a history of fever or measured fever of $\geq 38^{\circ} \mathrm{C}$ and cough, with onset during the preceding 10 days $[8,9]$.

All patients presenting to one of the sentinel general practices with suspected respiratory infections were screened by the general practitioner or nurse for ILI. All identified ILI cases were entered on an electronic form in the practice management system and a nasopharyngeal or throat swab was collected for influenza virus testing from all consenting patients.
For hospitalised patients, we enrolled individuals aged six months and older who were admitted with SARI to one of the four public hospitals covering the whole population in this catchment area. On the basis of the World Health Organization (WHO) definition, SARI was defined as hospitalisation with a patient-reported history of a fever or a measured temperature of $\geq 38^{\circ} \mathrm{C}$ and cough with onset within the past 10 days [10]. A confirmed case of influenza was defined as a SARI or ILI patient with a positive laboratory result for any influenza virus detected by real-time reverse transcription polymerase chain reaction (RT-PCR), while non-cases (controls) were patients with SARI or ILI who tested negative for all influenza viruses.

SARI patients were identified following screening of patients admitted with respiratory disease by dedicated research nurses. Overnight admissions of patients with respiratory symptoms were screened by the nurses on the following day. All patients satisfying the SARI case definition were invited to participate in the study. Patients who gave verbal consent completed a case report form and provided a nasopharyngeal swab or aspirate for influenza virus testing.

Patients who were identified at seven days post onset of symptoms were excluded from the ILI and SARI analysis, based on the pattern of shedding, which peaks in 
Study participants with severe acute respiratory infections who were influenza virus positive and negative by week, New Zealand, 2013 influenza season

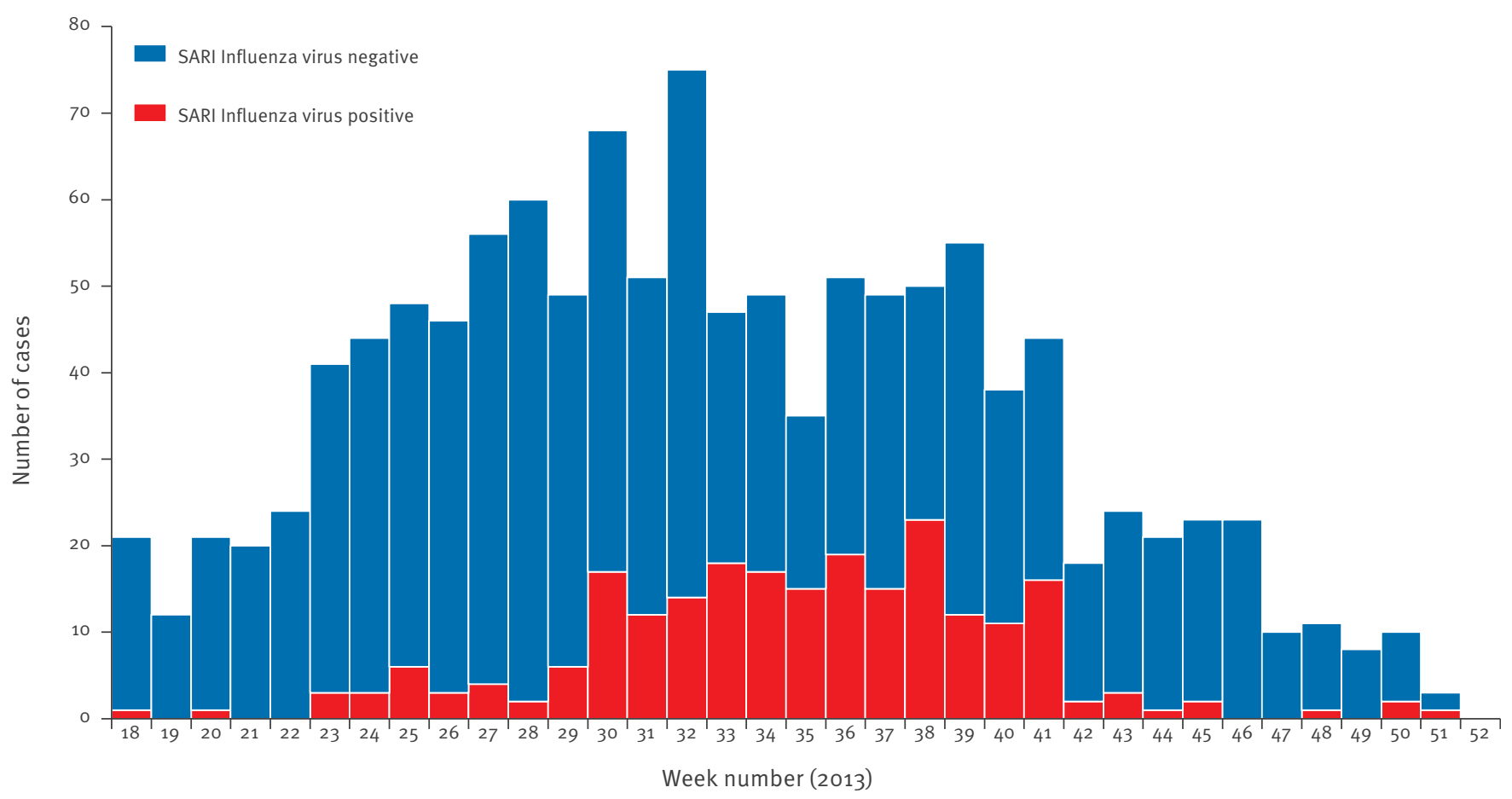

SARI: severe acute respiratory infection.

Weeks 18 to 52 are shown (20 April to 31 December 2014).

the first three days, then declines steadily until days 7-9 [9]. We also excluded patients with incomplete data for vaccination status or age, all infants under 6 months of age, children aged under 9 years who were only given one dose of trivalent inactivated influenza vaccine, patients who were vaccinated less than 14 days before admission to hospital or presentation to general practice. For patients with multiple episodes, the first influenza virus-positive episode was used for the analysis, or the first illness episode if there was no influenza virus-positive episode.

The influenza season was defined as starting when there were two consecutive weeks with two or more cases and ending when there were no consecutive weeks with two or more cases. Analysis was thus undertaken from 3 June to 10 November 2013 for SARI cases and from 13 May to 27 October 2013 for ILI cases (Figures 1 and 2).

\section{Participant information}

For all ILI patients, variables extracted from the electronic form and patient management system included age, sex, ethnicity, chronic medical conditions and current smoking status, socio-economic status as identified by the New Zealand deprivation status (a meshblock measure reflecting eight dimensions of deprivation distributed into deciles) [11] and a subjective assessment of obesity by the clinician as body mass index measurements were not consistently available.

Similar information was collected for all SARI patients, but for this group we also collected the following: a patient- or caregiver-reported measure of dependence (which assessed requirement for assistance with normal activity or full dependency on nursing care); a measure based on long-term use of oxygen that we labelled 'frailty'; a history of chronic medical conditions; and a self-defined, standardised functional wellbeing health status score from a national survey [12], combining fair or poor well-being versus all other more positive well-being scores.

In New Zealand, almost all influenza vaccinations are administered in general practices. For ILI cases, vaccination status was taken from the general practice record. SARI vaccination status for the 12 months before hospitalisation was determined by self-report.

\section{Laboratory methods}

Nasopharyngeal swabs, aspirates and other respiratory samples were collected according to hospital or general practice standard procedures. Samples were tested using the United States Centers for Disease Control and Prevention (CDC) real time RT-PCR protocol [13] or the AusDiagnostic PCR protocol [14]. The AusDiagnostic assay had a sensitivity of $100 \%$ and 
Characteristics of study participants with influenza-like illness and severe acute respiratory infection, New Zealand, 2013 influenza season*

\begin{tabular}{|c|c|c|c|c|}
\hline \multirow{2}{*}{ Characteristic } & \multicolumn{2}{|c|}{$\begin{array}{c}\text { Hospitalised with } \\
\text { severe acute respiratory infection }\end{array}$} & \multicolumn{2}{|c|}{$\begin{array}{l}\text { General practice visit for } \\
\text { influenza-like illness }\end{array}$} \\
\hline & $\begin{array}{l}\text { Cases } \\
\mathrm{n}(\%)^{\mathrm{a}}\end{array}$ & $\begin{array}{l}\text { Controls } \\
\mathrm{n}(\%)^{\mathrm{a}}\end{array}$ & $\begin{array}{l}\text { Cases } \\
\mathrm{n}(\%)^{\mathrm{a}}\end{array}$ & $\begin{array}{l}\text { Controls } \\
\mathrm{n}(\%)^{\mathrm{a}}\end{array}$ \\
\hline Vaccinated & $82(36.6)$ & $372(45.4)$ & $44(9.1)$ & $177(17.4)$ \\
\hline Median age in years & $49(21.9)$ & $41(5.0)$ & $25(5.2)$ & $21(2.1)$ \\
\hline Male & $105(46.9)$ & $410(50.1)$ & $224(46.5)$ & $415(41.0)$ \\
\hline \multicolumn{5}{|l|}{ Age group } \\
\hline 6 months -5 years & $40(17.9)$ & $271(33.1)$ & $74(15.4)$ & $255(25.2)$ \\
\hline $6-17$ years & $11(4.9)$ & $35(4 \cdot 3)$ & $141(29.3)$ & $221(21.8)$ \\
\hline $18-45$ years & $51(22.8)$ & $129(15.8)$ & $173(35.9)$ & $330(32.6)$ \\
\hline $46-64$ years & $51(22.8)$ & $156(19.1)$ & $75(15.6)$ & $159(15.7)$ \\
\hline $65-79$ years & $47(21.0)$ & $134(16.4)$ & $16(3.3)$ & $41(4.0)$ \\
\hline$\geq 80$ years & $24(10.7)$ & $93(11.4)$ & $3(0.6)$ & $7(0.7)$ \\
\hline \multicolumn{5}{|l|}{ Ethnicity } \\
\hline Pacific & $77(34.4)$ & $238(29.1)$ & $97(20.1)$ & $203(20.0)$ \\
\hline \multicolumn{5}{|l|}{ Other characteristics } \\
\hline Mean New Zealand deprivation score ${ }^{b}$ & $5 \cdot 3$ & 5.9 & 4.95 & 4.9 \\
\hline Pregnant & $5(2.2)$ & $5(0.6)$ & Not collected & Not collected \\
\hline Current smoker & $24(10.7)$ & $86(10.5)$ & $30(6.2)$ & $56(5.5)$ \\
\hline Chronic disease & $138(61.6)$ & $528(64.5)$ & Not collected & Not collected \\
\hline Obese $^{c}$ & $44(19.6)$ & $134(16.4)$ & $17(3.5)$ & $42(4.2)$ \\
\hline Self-defined well-being health status of poor or fair ${ }^{d}$ & $28(12.5)$ & $120(14.7)$ & Not collected & Not collected \\
\hline Frailty & $5(2.2)$ & $24(2.9)$ & Not collected & Not collected \\
\hline Dependence $^{f}$ & $10(4.5)$ & $50(6.1)$ & Not collected & Not collected \\
\hline Total & $224(100)$ & $818(100)$ & $482(100)$ & $1,013(100)$ \\
\hline
\end{tabular}

a Unless otherwise indicated.

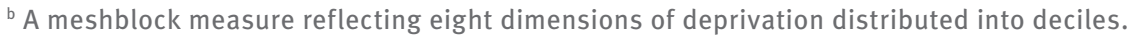

c Subjective assessment of obesity by the clinician.

${ }^{\mathrm{d}}$ A self-defined, standardised functional well-being health status score.

e Defined as currently on long-term oxygen use.

${ }^{f}$ Requirement for assistance with normal activity or full dependency on nursing care, as reported by the patient or caregiver.

specificity of $96.6 \%$ when the United States CDC method was used as the comparator [15]. RT-PCR assays detected influenza virus types $A$ and $B$ and subtyping was performed for type A. All influenza virus PCR-positive samples were forwarded to the National Influenza Centre and characterised antigenically using established methods [14].

\section{Statistical analysis}

Univariate chi-squared tests were used to compare characteristics of patients who were influenza virus positive (cases) and negative (controls). A multivariate logistic model restricted to the test-negative controls was used to calculate an adjusted odds ratio for the propensity to be vaccinated for a range of patient characteristics possibly associated with vaccination (Table 1) and used in a previous study [16]. The results from this propensity model are presented as odds ratios. This propensity model was then applied to the complete dataset to generate individual propensity scores for vaccination. In order to ensure these propensity scores were linear with respect to influenza virus positive status, we used the cubic spline for these scores as an adjustment variable for estimating VE. For both SARI and ILI, we calculated the crude VE, adjusting only for the timing of presentation relative to the influenza season (defined as weeks from the peak), and the adjusted VE, which included the timing of presentation and the cubic spline of the fitted values of the propensity model. VE estimates were calculated against both SARI and ILI, by influenza virus type and subtype and by age group (6 months-17 years, 18-64 years and $\geq 65$ years).

For all patient characteristics, other than age and vaccination status, each missing data point was imputed as the baseline (referent) value for the corresponding variable. The baseline values were: non-Māori, nonPacific ethnicity, female, not in New Zealand deprivation groups 8,9 or 10 (the three lowest deprivation deciles), not pregnant, current non-smoker, without chronic disease, not obese, with self-rated health average or better, not using long-term oxygen and living without assistance). All male patients and all female 


\section{FIGURE 3}

Flowchart of all selected, recruited and tested patients with influenza-like illness and severe acute respiratory infection for influenza vaccine effectiveness analysis, New Zealand, 2013 influenza season

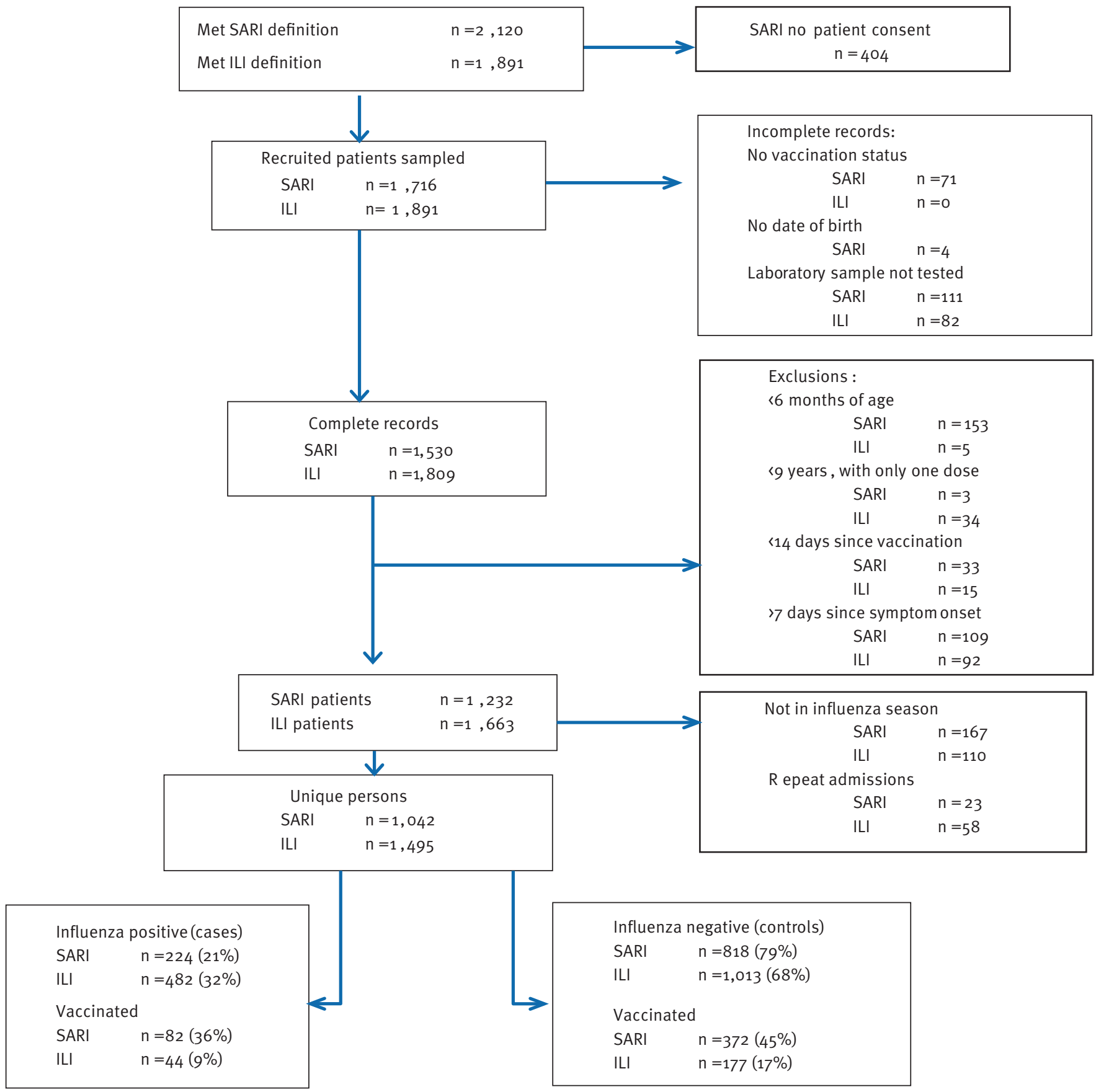

ILI: influenza-like illness; SARI: severe acute respiratory infection.

patients not aged $13-55$ years were assumed to be not pregnant. Overall, 53 SARI (5\%) cases and 1 ILI (0.1\%) case had any imputed covariates. Sensitivity analyses were performed using only those individuals with complete data.

As a further sensitivity analysis, we also compared the overall VE estimate from the propensity-adjusted model with an epidemiological model that included covariates that were assessed as potential confounders and/ or effect modifiers (Table 1) and a statistical model, derived from the epidemiological model, where only covariates that were significant at the 0.05 level were included in the final model.

\section{Results}

Characteristics and vaccination status of participants ILI and SARI patients in this study by influenza virus status are shown in Figures 1 and 2. 
Vaccinated and unvaccinated influenza cases by virus type and subtype in hospitalised and community study participants, New Zealand, 2013 influenza season*

\begin{tabular}{|c|c|c|c|c|}
\hline \multirow{2}{*}{$\begin{array}{l}\text { Influenza virus } \\
\text { type }\end{array}$} & \multicolumn{2}{|c|}{$\begin{array}{c}\text { Hospitalised with } \\
\text { severe acute respiratory infection }\end{array}$} & \multicolumn{2}{|c|}{$\begin{array}{l}\text { General practice visit for } \\
\text { influenza-like illness }\end{array}$} \\
\hline & Number vaccinated (\%) & Number unvaccinated (\%) & Number vaccinated (\%) & Number unvaccinated (\%) \\
\hline All & $82(100)$ & $142(100)$ & $44(100)$ & $438(100)$ \\
\hline $\mathrm{A}\left(\mathrm{H}_{1} \mathrm{~N}_{1}\right)$ & $5(6)$ & $8(6)$ & $3(7)$ & $27(6)$ \\
\hline $\mathrm{A}\left(\mathrm{H}_{3} \mathrm{~N}_{2}\right)$ & $51(62)$ & $68(48)$ & $20(45)$ & $196(45)$ \\
\hline All $A^{a}$ & $68(83)$ & $95(67)$ & $28(64)$ & $262(60)$ \\
\hline All B & 14 (17) & $48(34)$ & $16(36)$ & $180(41)$ \\
\hline
\end{tabular}

ILI: influenza-like illness; SARI: severe acute respiratory infection.

a One SARI case and four ILI cases tested positive for both influenza A and B viruses. Not all cases of influenza A were subtyped. The number of subtypes does not add up to the number of all influenza A viruses identified.

A total of 1,042 SARI admissions and 1,495 ILI patients were included in the analysis, of whom 224 (21\%) and 482 (32\%) were influenza virus positive, respectively. Of the 224 SARI admissions who tested influenza virus positive, 82 (37\%) were vaccinated, compared with $372 / 818$ (45\%) who tested negative. Despite our attempts, we were unable to verify self-reported vaccination status of SARI patients with the vaccine providers.

Of the 482 ILI patients who tested influenza virus positive, 44 (9\%) were vaccinated, compared with 177/1,013 $(17 \%)$ who tested negative (Figure 3$)$. The proportion vaccinated did not change throughout the season. In those excluded because of incomplete laboratory tests, self-reported vaccination in the previous 12 months among SARI cases was 49/135 (36\%), slightly less than the proportion of included SARI cases, 454/1,042 (44\%). In the ILI cases, the proportion vaccinated was much higher, at $8 / 21$ (38\%), in those excluded because of incomplete laboratory tests compared with the ILI cases included, of whom 9\% (44/482) were vaccinated.

Influenza-positive cases and influenza-negative controls were compared across a range of patient characteristics. SARI and ILI patients who were aged 6 months to 5 years or over 80 years, and those presenting outside the influenza season were less likely to test positive. In comparison with the community patients, the hospitalised patients were more likely to be vaccinated, to be older, to live in a deprived area, to be of Māori or Pacific ethnicity, to be a current smoker and to be obese (Table 1). Details on pregnancy were poorly recorded but less than $3 \%(30 / 1,042)$ of other data fields were missing for both SARI and ILI patients.

Of the 706 influenza cases detected in both SARI and ILI patients, 453 (64\%) were type A, 335 (47\%) $A\left(\mathrm{H}_{3} \mathrm{~N}_{2}\right)$, $43(6 \%) \mathrm{A}\left(\mathrm{H}_{1} \mathrm{~N}_{1}\right)$ and $75(11 \%) \mathrm{A}$ not subtyped) and 258 (37\%) type B (107 B/Wisconsin/1/2010-like of the B/ Yamagata lineage, 2 (0.3\%) B/Brisbane/6o/2008-like

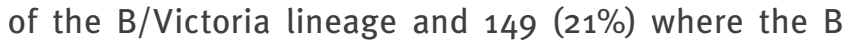

lineage was not determined). Five cases (0.7\%) tested positive for both influenza $A$ and $B$ (Table 2).

Although vaccination was more common in SARI patients, the same factors affected the propensity to be vaccinated in persons with ILI or SARI. The adjusted odds ratios for the association of various patient characteristics with the likelihood of vaccination showed that older age groups and those with chronic diseases were most likely to be vaccinated (Table 3). In contrast, there was no statistically significant difference in the likelihood of vaccination by ethnicity, sex, deprivation score, pregnancy, obesity, self-rated health, smoking, assisted living or the timing of the admission relative to the influenza season (Table 3).

\section{Vaccine effectiveness}

The VE against all circulating influenza virus strains, adjusted only for the number of weeks from the peak of the influenza season, was 32\% (95\% confidence interval (CI): 7 to 50) for influenza-confirmed SARI and $56 \%$ (95\% Cl: 37 to 70 ) for influenza-confirmed ILI (Table 4). After also adjusting for the propensity to be vaccinated, the estimated VE was $52 \%$ ( $95 \% \mathrm{Cl}: 32$ to 66) for SARI and $56 \%$ (95\% Cl: 34 to 70 ) for ILI. Thus, adjusting for the propensity to be vaccinated had more effect on the VE estimate for SARI than for ILI. For ILI, the crude and adjusted VE point estimates were the same.

There was no significant change to these estimates when excluding patients with missing values (for SARI, unadjusted VE was $29 \%$ ( $95 \% \mathrm{Cl}: 3$ to 48 ) and adjusted VE $50 \%$ (95\% Cl: 29 to 66); for ILI, unadjusted VE was $56 \%$ (95\% Cl: 37 to 70 ) and adjusted VE 56\% (95\% Cl: 34 to 70)). When a logistic regression model was constructed and directly adjusted for all the covariates in Table 1 , the VE was $54 \%$ (95\% Cl: 33 to 69) for SARI admissions and 58\% (95\% Cl: 37 to 72 ) for ILI patients. Adjusting for only the variables that were significant in the model ( $p<0.05$ ) resulted in a VE estimate of $54 \%$ (95\% Cl: 33 to 69 ) for SARI and 59\% (95\% Cl: 41 to 72 ) for ILI. When restricting the analysis to within four days of onset of symptoms, the adjusted VE for ILI was 
Characteristics of non-influenza virus-positive study patients with severe acute respiratory infection and influenza-like illness (controls) and their association with influenza vaccination status, New Zealand, 2013 influenza season

\begin{tabular}{|c|c|c|c|c|}
\hline \multirow[t]{2}{*}{ Characteristic } & \multicolumn{2}{|c|}{$\begin{array}{l}\text { Hospitalised with } \\
\text { severe acute respiratory infection }\end{array}$} & \multicolumn{2}{|c|}{$\begin{array}{l}\text { General practice visit for influenza- } \\
\text { like illness }\end{array}$} \\
\hline & OR $(95 \% \mathrm{Cl})$ & $P$ value & OR $(95 \% \mathrm{Cl})$ & $P$ value \\
\hline \multicolumn{5}{|l|}{ Age group } \\
\hline 6 months -5 years & $0.15(0.08$ to 0.27$)$ & $<0.01$ & $0.14(0.07$ to 0.25$)$ & $<0.01$ \\
\hline $6-17$ years & 0.26 (0.11 to 0.63$)$ & $<0.01$ & $0.19(0.11$ to 0.34$)$ & $<0.01$ \\
\hline $18-45$ years & 0.42 (0.25 to 0.70$)$ & $<0.01$ & $0.31(0.20$ to 0.50$)$ & $<0.01$ \\
\hline $65-79$ years & 2.28 (1.30 to 4.00$)$ & $<0.01$ & $7.9(3.35$ to 18.64$)$ & 0.01 \\
\hline$\geq 80$ years & $2.81(1.38$ to 5.73$)$ & $<0.01$ & $8.87(1.01$ to 77.66$)$ & 0.05 \\
\hline \multicolumn{5}{|l|}{ Ethnicity } \\
\hline Māori & $0.72(0.44$ to 1.17$)$ & 0.19 & $0.60(0.25$ to 1.47$)$ & 0.26 \\
\hline Pacific & $0.94(0.59$ to 1.49$)$ & 0.79 & 0.68 (0.38 to 1.22$)$ & 0.19 \\
\hline \multicolumn{5}{|l|}{ Additional characteristics } \\
\hline Male & $1.02(0.71$ to 1.45$)$ & 0.92 & $0.64(0.43$ to 0.96$)$ & 0.03 \\
\hline Mean New Zealand deprivation score ${ }^{\mathrm{a}}$ & 0.98 (0.91 to 1.05$)$ & 0.53 & 0.98 (0.91 to 1.06$)$ & 0.61 \\
\hline Pregnant & 1.28 (0.19 to 8.50$)$ & 0.80 & Not collected & - \\
\hline Current smoker & $0.92(0.54$ to 1.56$)$ & 0.74 & $0.57(0.26$ to 1.26$)$ & 0.16 \\
\hline Chronic disease & 2.65 (1.64 to 4.26$)$ & $<0.01$ & 2.07 (1.38 to 3.09$)$ & $<0.01$ \\
\hline Obese $^{\mathrm{b}}$ & 1.18 (0.73 to 1.92$)$ & 0.50 & $1.08(0.45$ to 2.56$)$ & 0.87 \\
\hline Self-defined well-being health status of poor or fair ${ }^{c}$ & $1.03(0.62$ to 1.71$)$ & 0.92 & Not collected & - \\
\hline Frailty $^{\mathrm{d}}$ & 3.25 (0.96 to 11.07 ) & 0.06 & Not collected & - \\
\hline Dependence ${ }^{\mathrm{e}}$ & 1.25 (0.55 to 2.83$)$ & 0.6 & Not collected & - \\
\hline Early in influenza season ${ }^{f}$ & Not applicable & - & 1.07 (0.68 to 1.67$)$ & 0.78 \\
\hline
\end{tabular}

OR: adjusted odds ratio compared with referent group: female, aged 46-64 years, non-Māori, non-Pacific ethnicity, not in the New Zealand deprivation measure of the three lowest deciles (8,9 or 10), not pregnant, current non-smoker, without chronic disease, not obese, with self-rated health average or better, not on long-term oxygen use, living without assistance and admitted to hospital for severe acute respiratory infection during the peak influenza season.

a A meshblock measure reflecting eight dimensions of deprivation distributed into deciles.

b Subjective assessment of obesity by the clinician.

A self-defined, standardised functional well-being health status score.

Defined as currently on long-term oxygen use.

Requirement for assistance with normal activity or full dependency on nursing care, as reported by the patient or caregiver.

Admission or presentation before 1 June 2013.

$48 \%(95 \% \mathrm{Cl}: 3$ to 68$)$ and for SARI $57 \%(95 \% \mathrm{Cl}: 36$ to 71). When analysed by restricting to a shorter period around the peak (weeks 28-40), the VE for ILI was $46 \%$ (95\% Cl: 16 to 65 ) and for SARI 53\% (95\% Cl: 27 to 50). For both SARI and ILI influenza-positive cases, the vaccination rate was constant over time.

The vaccine was significantly protective among patients aged $18-64$ years. Specifically, VE was $61 \%$ (95\% Cl: 34 to 77 ) against SARI and 55\% (95\% CI: 24 to 73) against ILI. Although with wider Cls, the vaccine was also signficantly protective for those aged 0-17 years, with an estimated VE of $78 \%$ for SARI $(95 \% \mathrm{CI}: 2$ to 95 ) and $56 \%$ for ILI ( $95 \% \mathrm{Cl}: 6$ to 79 ). For those aged 65 years and older, VE point estimates were lower for SARI at 34\%, although Cls crossed zero (95\% Cl: -28 to 66 ), and higher for ILI at $76 \%$ although with wide Cls (95\% Cl: 15 to 93) (Table 4).

For SARI patients, VE against influenza A was $39 \%$ (95\% Cl: 10 to 58 ) and against influenza B was $76 \%$ ( $95 \% \mathrm{Cl}: 54$ to 87 ). For ILI patients, VE against influenza
A was $58 \%(95 \% \mathrm{Cl}: 32$ to 74$)$ and against influenza $\mathrm{B}$ $54 \%$ (95\% Cl: 19 to 75 ) (Table 4).

The influenza viruses isolated from all of New Zealand during February to September 2013 were forwarded to the WHO Collaborating Centre for Research and Surveillance of Influenza in Melbourne, Australia, for further antigenic characterisation. Most of the New Zealand influenza $A\left(\mathrm{H}_{1} \mathrm{~N}_{1}\right)$ viruses reacted well with ferret antisera raised against $A / C a l i f o r n i a / 7 / 2009$ virus. Almost all of the $A\left(\mathrm{H}_{3} \mathrm{~N}_{2}\right)$ viruses reacted well with ferret antisera raised against cell-propagated $\mathrm{A} /$ Victoria/361/2011 or A/Texas/50/2012 viruses. B/ Yamagata lineage viruses were the predominant $B$ viruses in New Zealand in 2013. Although this lineage was included in the 2013 southern hemisphere vaccine formulation, antigenic drift was observed in these viruses, as they reacted better with ferret sera raised against B/Massachusetts/2/2012-like virus (selected for the southern hemisphere 2014 vaccine) than $B /$ Wisconsin/1/2010 virus (included in the southern hemisphere 2013 vaccine). 
Estimated influenza vaccine effectiveness, by participant age group and by influenza virus type and subtype: crude and propensity adjusted models, New Zealand, 2013 influenza season

\begin{tabular}{|c|c|c|c|c|}
\hline \multirow{3}{*}{ Influenza virus and age group } & \multicolumn{2}{|c|}{$\begin{array}{l}\text { Hospitalised with } \\
\text { severe acute respiratory infection }\end{array}$} & \multicolumn{2}{|c|}{$\begin{array}{l}\text { General practice visit for } \\
\text { influenza-like illness }\end{array}$} \\
\hline & Crude model $^{\mathrm{a}}$ & $\begin{array}{c}\text { Propensity adjusted } \\
\text { model }^{\mathrm{a}}\end{array}$ & Crude model $^{\mathrm{a}}$ & $\begin{array}{c}\text { Propensity adjusted } \\
\text { model }^{\mathrm{a}}\end{array}$ \\
\hline & $\operatorname{VE}(95 \% \mathrm{Cl})$ & VE $(95 \% \mathrm{Cl})$ & VE $(95 \% \mathrm{Cl})$ & VE $(95 \% \mathrm{Cl})$ \\
\hline \multicolumn{5}{|l|}{ Influenza virus type or subtype } \\
\hline Overall & 32 (7 to 50$)$ & $52(32$ to 66$)$ & 56 (37 to 70$)$ & $56(34$ to 70$)$ \\
\hline $\mathrm{A}\left(\mathrm{H}_{1} \mathrm{~N}_{1}\right)$ & $25(-132$ to 76$)$ & $48(-74$ to 85$)$ & $50(-68$ to 85$)$ & $49(-90$ to 86$)$ \\
\hline $\mathrm{A}\left(\mathrm{H}_{3} \mathrm{~N}_{2}\right)$ & $11(-33$ to 40$)$ & $34(-2$ to 57$)$ & $56(27$ to 74$)$ & $61(32$ to 77$)$ \\
\hline All A & 15 ( -21 to 40$)$ & 39 (10 to 58$)$ & $55(29$ to 71$)$ & $58(32$ to 74$)$ \\
\hline All B & $65(36$ to 81$)$ & 76 (54 to 87$)$ & 60 (32 to 77$)$ & $54(19$ to 75$)$ \\
\hline \multicolumn{5}{|l|}{ Age group } \\
\hline 6 months -17 years & $72(-22$ to 93$)$ & 78 (2 to 95$)$ & $56(6$ to 79$)$ & $56(6$ to 79$)$ \\
\hline $18-64$ years & $66(43$ to -79$)$ & $61(34$ to 77$)$ & $59(32$ to 75$)$ & 55 (24 to 73$)$ \\
\hline$\geq 65$ years & $35(-25$ to 66$)$ & $34(-28$ to 66$)$ & 74 (12 to 92$)$ & 76 (15 to 93) \\
\hline
\end{tabular}

VE: vaccine effectiveness, as a percentage.

${ }^{a}$ All models were adjusted for the number of weeks from the influenza peak.

\section{Discussion}

The 2013 New Zealand influenza season was characterised by low incidence and a late peak, with influenza $A\left(\mathrm{H}_{3} \mathrm{~N}_{2}\right)$ and influenza $B$ most commonly detected. The circulating influenza $A$ subtypes were antigenically similar to the $\mathrm{H}_{1}$ and $\mathrm{H}_{3}$ components of the 2013 vaccine, while the predominant circulating $B$ viruses were lineage matched, although antigenic drift was observed.

This is the first study comparing VE against medically attended ILI and hospitalised SARI due to laboratoryconfirmed influenza from the same population in the same season in New Zealand. The ILI surveillance season started and finished two weeks earlier than SARI surveillance. This may reflect a delay between onset of cases in the community and their referral to hospital.

After adjustment for the propensity to be vaccinated, we found moderate VE, around $50 \%$, against both ILI and SARI, suggesting there was unlikely to be a substantial difference in VE by severity of influenza illness. However, the study was not powered to test for this difference. In addition, the patient groups differed by a number of important factors including age and ethnicity. The propensity score among patients with SARI varied much more than among those with ILI, due to the increased likelihood of vaccination among SARI patients and more available data on covariates. In particular, influenza was more often detected in the older age groups in the SARI patients and the adjustment for the propensity score therefore had a bigger effect for SARI patients. There was no significant change to VE estimates when the analysis was restricted to four days post onset of symptoms, rather than seven days.
The vaccine showed significant effectiveness against influenza A for ILI and SARI patients, with protection estimated to be lower for SARI patients. On the other hand, protection against influenza $B$ appeared higher for the SARI patients, but the Cls overlapped for all comparisons. The vaccine prevented about $55-60 \%$ of ILI presentations and SARI hospitalisations in the 18-64-year age group. In the younger age group, the vaccine appeared to be more effective against SARI presentations compared with ILI, but the Cls were wide. The sample size was too small to make definitive VE estimates for the older age group.

Our point estimate for VE against medically attended influenza-confirmed ILI was very similar to northern hemisphere estimates for the 2012/13 influenza season, with interim adjusted estimates of $56 \%(95 \% \mathrm{Cl}$ : 47 to 63 ) from the United States [17], a United Kingdom mid-season estimate of $51 \%(95 \% \mathrm{Cl}: 27$ to 68$)$ [18] and a Canadian estimate of $50 \%(95 \% \mathrm{Cl}: 33$ to 63$)$ [19]. Similarly, VE results for ILI in the 2012/13 season from seven study sites in Europe reported the same virus circulation and adjusted estimates for the three circulating strains of $49 \%(95 \% \mathrm{Cl}: 32.4$ to 62 ) for influenza B, $50 \%(95 \% \mathrm{Cl}: 28.4$ to 65.6$)$ for $\mathrm{A}\left(\mathrm{H}_{1} \mathrm{~N}_{1}\right)$ and $42 \%$ (95\% Cl: 14.9 to 60.7$)$ for $\mathrm{A}\left(\mathrm{H}_{3} \mathrm{~N}_{2}\right)$ [20].

While we collected information on most suspected potential confounding variables, we could not control for residual confounders. In future years, we will collect data on previous presentations with respiratory illnesses and previous vaccination. New Zealand has added influenza vaccination to its national 
immunisation register from 2014. This will provide more accurate vaccination history for SARI cases than patient self-report.

In conclusion, this study shows a moderate protective effectiveness of influenza vaccine against medicallyattended and hospitalised influenza, generally supporting the current national immunisation strategy in New Zealand. Pooled data from future years of the SHIVERS study will allow more precise VE estimates for high-risk subgroups and will also allow more extensive comparisons between VE estimates in primary care (general practice) and hospital settings.

Southern Hemisphere Influenza Vaccine Effectiveness, Research and Surveillance (SHIVERS) investigation team (listed in an alphabetic order)

Bruce Adlam, Debbie Aley, Don Bandaranayake, John Cameron, Kirsten Davey, Gillian Davies, Jazmin Duque, Leane Els, Cameron C. Grant, Rosemary Gordon, Diane Gross, Marion Howie, Graham Mackereth, Barbara McArdle, Colin McArthur, Barbara McArdle, Gary Reynolds, Sally Roberts, Ruth Seeds, Susan Taylor, Paul Thomas, Mark Thompson, Adrian Trenholme, Richard Webby, Deborah A. Williamson, Conroy Wong, Tim Wood, Sam Wong.

\section{Acknowledgements}

The SHIVERS (Southern Hemisphere Influenza and Vaccine Effectiveness Research and Surveillance) project is funded by the United States Department of Health and Human Services, Centers for Disease Control and Prevention (CDC) (1U01lP000480-01).

WHO Collaborating Centre for Research and Surveillance of Influenza, Melbourne, and NIC at ESR for supplying antigenic typing results for influenza isolates.

\section{Conflict of interest}

None declared.

\section{Authors' contributions}

Nikki Turner: principal investigator, involved in study design, implementation, analysis, manuscript development. Nevil Pierse: involved in study design, methodological design, data analysis, interpretation and manuscript development. Ange Bissielo: involved in study design, data collection and analysis, and manuscript development. Q Sue Huang: principal investigator for the larger SHIVERS study, involved in study design, implementation, and manuscript development. Sarah Radke: involved in data collection, analysis, interpretation and manuscript development. Michael Baker: involved in study design, data interpretation and manuscript development. Marc-Alain Widdowson: involved in study design, analysis, interpretation and manuscript development. Heath Kelly: involved in study design, methodological analysis, data analysis and interpretation, manuscript development and editing.

\section{* Erratum:}

In Table 2, the column headings for number and percentage unvaccinated were incorrectly labelled. This was corrected on 29 August 2014. In addition, in Table 1, the column headings for cases and controls were incorrectly labelled. This was corrected on 22 June 2015 .

\section{Reference}

1. Nair H, Brooks WA, Katz M, Roca A, Berkley JA, Madhi SA, et al. Global burden of respiratory infections due to seasonal influenza in young children: a systematic review and metaanalysis. Lancet. 2011;378(9807):1917-30. http://dx.doi. org/10.1016/S0140-6736(11)61051-9

2. Carrat F, Sahler C, Rogez S, Leruez-Ville M, Freymuth F, Le Gales C, et al. Influenza burden of illness: estimates from a national prospective survey of household contacts in France. Arch Intern Med. 2002;162(16):1842-8. http://dx.doi. org/10.1001/archinte.162.16.1842

3. Manzoli L, Ioannidis JP, Flacco ME, De Vito C, Villari P. Effectiveness and harms of seasonal and pandemic influenza vaccines in children, adults and elderly: a critical review and re-analysis of 15 meta-analyses. Hum Vaccin Immunother. 2012;8(7):851-62. http://dx.doi.org/10.4161/hv.19917

4. Jefferson T, Smith S, Demicheli V, Harnden A, Rivetti A, Di Pietrantonj C. Assessment of the efficacy and effectiveness of influenza vaccines in healthy children: systematic review. Lancet. 2005;365(9461):773-80. http://dx.doi.org/10.1016/ So140-6736(05)17984-7

5. Osterholm MT, Kelley NS, Sommer A, Belongia EA. Efficacy and effectiveness of influenza vaccines: a systematic review and metaanalysis. Lancet Infect Dis. 2011;12(1):36-44. http:// dx.doi.org/10.1016/S1473-3099(11)70295-X

6. Foppa IM, Haber M, Ferdinands JM, Shay DK. The case test-negative design for studies of the effectiveness of influenza vaccine. Vaccine. 2013;31(30):3104-9. http://dx.doi. org/10.1016/j.vaccine.2013.04.026

7. Statistics New Zealand (NZ). 2013 Census. Wellington: Statistics NZ. [Accessed 28 Aug 2014]. Available from: http:// www.stats.govt.nz/Census/2013-census.aspx

8. World Health Organization (WHO) Regional Office for Europe. WHO Regional Office for Europe guidance for influenza surveillance in humans. Copenhagen: WHO Regional Office for Europe; 2009. [Accessed 16 Mar 2011]. Updated May 2011 document available from: http://www.euro.who.int/_data/ assets/pdf_file/0020/90443/E92738.pdf

9. Suess T, Remschmidt C, Schink SB, Schweiger B, Heider A Milde J, et al. Comparison of shedding characteristics of seasonal influenza virus (sub) types and influenza $A\left(\mathrm{H}_{1} \mathrm{~N}_{1}\right)$ pdmo9; Germany, 2007-2011. PloS One. 2012;7(12):e51653. http://dx.doi.org/10.1371/journal.pone.0051653

10. World Health Organization (WHO). Interim epidemiological surveillance standards for influenza. Geneva: WHO; 2012. [Accessed 4 Sep 2013]. Global epidemiological surveillance standards for influenza, 2013, available from: http://www.who.int/influenza/resources/documents/ influenza_surveillance_manual/en/

11. Crampton P, Salmon C, Kirkpatrick R. Degrees of deprivation in New Zealand: an atlas of socioeconomic difference. 2nd ed. Auckland: David Bateman Ltd; 2004.

12. Jenkinson C, Coulter A, Wright L. Short form 36 (SF36) health survey questionnaire: normative data for adults of working age. BMJ. 1993;306(6890):1437-40. http://dx.doi.org/10.1136/ bmj.306.6890.1437

13. Shu B, Wu KH, Emery S, Villanueva J, Johnson R, Guthrie E, et al. Design and performance of the CDC real-time reverse transcriptase PCR swine flu panel for detection of $2009 \mathrm{~A}\left(\mathrm{H}_{1} \mathrm{~N}_{1}\right)$ pandemic influenza virus. J Clin Microbiol. 2011;49(7):2614-9. http://dx.doi.org/10.1128/JCM.02636-10

14. Szewczuk E, Thapa K, Anninos T, McPhie K, Higgins G, Dwyer $D E$, et al. Rapid semi-automated quantitative multiplex tandem PCR (MT-PCR) assays for the differential diagnosis of influenzalike illness. BMC Infect Dis., 2010;10:113. http://dx.doi. org/10.1186/1471-2334-10-113 
15. Hunag Q, Baker M, McArthur C, Roberts S, Williamson D, Grant $C$, et al. Implementing hospital-based surveillance for severe acute respiratory infections caused by influenza and other respiratory pathogens in New Zealand. Western Pac Surveill Response J. 2014;5(2):23-30. http://dx.doi.org/10.5365/ wpsar.2014.5.1.004

16. Talbot HK, Griffin MR, Chen Q, Zhu Y, Williams JV, Edwards KM. Effectiveness of seasonal vaccine in preventing confirmed influenza-associated hospitalizations in community dwelling older adults. J Infect Dis. 2011;203(4):500-8. http://dx.doi. org/10.1093/infdis/jiq076

17. Centers for Disease Control and Prevention (CDC).

Interim adjusted estimates of seasonal influenza vaccine effectiveness-United States, February 2013. MMWR Morb Mortal Wkly Rep. 2013. 62(7):119-23.

18. McMenamin J, Andrews N, Robertson C, Fleming D, Durnall $\mathrm{H}$, von Wissmann B, et al. Effectiveness of seasonal 2012/13 vaccine in preventing laboratory-confirmed influenza infection in primary care in the United Kingdom: mid-season analysis 2012/13. Euro Surveill. 2013;18(5): pii=20393.

19. Skowronski DM, Janjua NZ, De Serres G, Sabaiduc S,

Eshaghi A, Dickinson JA, et al. Low 2012-13 influenza vaccine effectiveness associated with mutation in the egg-adapted $\mathrm{H}_{3} \mathrm{~N}_{2}$ vaccine strain not antigenic drift in circulating viruses. PloS One. 2014;9(3):e92153. http://dx.doi.org/10.1371/journal. pone.0092153

20. Kissling E, Valenciano M, Buchholz U, Larrauri A, Cohen JM, Nunes B, et al. Influenza vaccine effectiveness estimates in Europe in a season with three influenza type/subtypes circulating: the I-MOVE multicentre case-control study, influenza season 2012/13. Euro Surveill. 2014;19(6): pii=20701. 